\title{
Estresses financeiros na economia brasileira durante o regime de metas para inflação *
}

\author{
Douglas Marcos Ferreira \\ Leonardo Bornacki de Mattos ${ }^{* * *}$
}

\begin{abstract}
Resumo
As crises financeiras ocorridas nas últimas décadas trouxeram novos desafios para as autoridades monetárias de países desenvolvidos e em desenvolvimento no sentido de incluírem em suas agendas questões relacionadas à estabilidade financeira. O presente trabalho construiu o Índice de Estresse Financeiro (F.S.I.) para identificar e caracterizar os episódios de estresses financeiros que atingiram a economia brasileira durante o regime de metas para inflação. Foram identificados 5 episódios de estresse com duração igual ou superior a três meses, dos quais 4 associaram-se a crises que impactaram a economia, a saber: crise de confiança (2002), crise do subprime (2008), crise da zona do euro (2011) e a crise política e econômica (2014). As instabilidades nos setores cambial e acionário potencializaram os principais episódios de estresses financeiros que atingiram a economia brasileira. Os resultados mostraram que o F.S.I. pode ser uma ferramenta útil para o Banco Central do Brasil no contexto de identificação e caracterização de episódios que gerem estresses financeiros na economia.
\end{abstract}

Palavras-chave: Estresse financeiro; Índice de estresse financeiro; Crises financeiras; Política Monetária; Banco Central.

\section{Abstract \\ Financial stress in the Brazilian economy during an inflation targeting regime}

Financial crises that have occurred in recent decades brought new challenges for policymakers in developed and developing countries in order to include issues related to financial stability. This paper aimed to build a Financial Stress Index (FSI) to identify and characterize episodes of financial stress that affected the Brazilian economy during an inflation targeting regime. Five episodes of stress with a duration of greater or equal to three months were identified. Four of them were associated with crises that impacted the Brazilian economy: the economic confidence crisis (2002); crisis of subprime (2008); crisis in the euro zone (2011) and the political and economic crisis (2014). The instability in the foreign exchange and stock market enhanced the impact of major episodes of financial stresses on the Brazilian economy. Results showed that the F.S.I. can be a useful tool for the Brazilian Central Bank to identify such episodes which generate financial stress in the economy.

Keywords: Financial stress; Financial stress index; Financial crises; Monetary economy; Central Banking.

JEL E5, E6, G2,

\footnotetext{
* Artigo recebido em 26 de janeiro de 2016 e aprovado em 01 de outubro de 2016.

*** Professor Adjunto do Departamento de Ciências Econômicas - Universidade Federal de São João del Rei (UFSJ), São João del Rei, MG, Brasil. E-mail: douglasferreira@ufsj.edu.br.

${ }^{* * *}$ Professor Associado do Departamento de Economia Rural - Universidade Federal de Viçosa (UFV), Viçosa, MG, Brasil. E-mail: lbmattos@ufv.br.
} 


\section{Introdução}

As crises financeiras ocorridas desde o fim dos anos de 1980 trouxeram novos desafios para as autoridades monetárias de países desenvolvidos e em desenvolvimento. A bolha nos preços imobiliários em Tóquio, no fim dos anos 80 , a crise financeira do sudeste asiático, em 1997/1998, a crise financeira internacional no mercado americano das subprimes, em meados de 2007, e a crise da zona do euro, em 2011, entre outras, acarretaram novas implicações para a condução da política monetária dos bancos centrais no sentido desses incluírem em suas agendas questões relacionadas à estabilidade financeira.

Parte da atenção devotada às questões financeiras pelas autoridades monetárias se deu em função da importância do sistema financeiro para a estabilidade macroeconômica dos países. Segundo Das et al. (2004), crises financeiras tendem a ter custos significativos do ponto de vista macroeconômico, com possíveis efeitos negativos sobre o crescimento, redução da eficácia da política monetária e efeitos de contágio para outras economias. Dessa forma, deficiências nos sistemas financeiros podem refletir na intermediação ineficiente de poupança, tornar a transmissão da política monetária menos eficaz, além de graves consequências fiscais. Em períodos de instabilidades financeiras, dois tipos de riscos afetam a economia em geral. Conforme ressaltado por Mishkin (2009), o primeiro desses riscos é o de avaliação, relacionado à dificuldade do mercado em avaliar o valor dos ativos em função de sua complexidade e da falta de transparência de sua solidez. O segundo risco é o macroeconômico, ligado ao aumento na probabilidade de que uma instabilidade financeira ocasione grande deterioração da economia real. Isso se deve ao fato das tensões financeiras ocasionarem desaceleração econômica, e essa por sua vez afetar o valor dos ativos, gerando assim um circuito de retroalimentação.

Convém, ainda, ressaltar, conforme explicitado por Houben et al. (2004), que a ênfase na estabilidade financeira também foi reflexo do processo de expansão, liberalização e globalização dos sistemas financeiros. Nesse sentido, o que se observou com a intensificação da globalização financeira foi o aumento da instabilidade econômica mundial. Como destacam Terra e Soihet (2006), a elevação do fluxo de capitais internacionais associou-se à ocorrência de crises de caráter financeiro em escala mundial, despertando o interesse de investigações quanto ao grau de exposição dos países a choques financeiros na economia global.

Ressalta-se, ainda, o fato da relevância em torno das instabilidades financeiras ganhar novo contorno dentro do regime de metas para a inflação. Em síntese, neste novo consenso de política monetária, adotado de maneira formal inicialmente pela Nova Zelândia, em 1989, o objetivo primordial da política dos bancos centrais é o de garantir a estabilidade dos preços, sendo a taxa de juros o 
principal instrumento para se alcançar este objetivo. No processo de definição da taxa de juros a política monetária está propensa a reagir aos episódios de instabilidades financeiras de duas maneiras (Goodhart et al., 2009). A primeira delas trata de cenários nos quais o sistema financeiro encontra-se estável, de modo que a definição da taxa de juros refletirá as condições macroeconômicas, fato que, consequentemente, limita as discussões sobre a instabilidade financeira nesse processo. A segunda está relacionada a casos nos quais o sistema financeiro encontra-se sob estresses ou instabilidades e o Banco Central pode alterar a taxa de juros a fim de minimizar os efeitos dessas instabilidades para a economia. Por fim, um sistema financeiro estável aumenta a estabilidade de preços da economia ao promover maior eficácia da política monetária. Neste contexto, Papademos (2009) afirma que a estabilidade financeira facilita a transmissão da política monetária, ao conter a propagação e os impactos de choques econômicos por meio do setor financeiro.

Na última década, a crise financeira internacional do subprime forneceu claras evidências de que mesmo o ambiente econômico favorável antes de sua eclosão, caracterizado por inflação estável e crescimento econômico, não impediu os desequilíbrios e as instabilidades no mercado financeiro brasileiro, assim como em grande parte das economias mundiais. Inserido neste contexto, Papademos (2009) e Apostoaie e Cuza (2010) argumentam que um consenso que surgiu após a crise é que os bancos centrais têm importante papel em promover a estabilidade financeira, e que em muitas situações, como a verificada na crise, manter a estabilidade financeira é mais importante que a busca pela estabilidade de preços, sendo essa última a função primordial de grande parte dos bancos centrais ${ }^{1}$.

Apesar do amplo conhecimento das causas e efeitos das recentes crises financeiras, encontrar uma medida para mensurar os cenários de instabilidades financeiras é uma das prioridades para qualquer autoridade monetária que busque promover a estabilidade de seu sistema financeiro, como ressaltado por Sales et al. (2012). Segundo Illing e Liu (2006), há pouco interesse, na literatura sobre crises financeiras, em se medir a gravidade contemporânea destas crises. Os autores ainda argumentam que as crises financeiras são usualmente consideradas como fenômenos bancários e/ou, relacionados à moeda, ao invés de considerarem o sistema financeiro como um todo. Devido à complexidade do sistema financeiro, a construção de um índice para avaliar cenários de instabilidades financeiras não deve ter como foco específico apenas um setor/segmento, mas fornecer uma análise mais ampla do sistema como um todo. Soma-se a isso o fato de grande parte dos trabalhos

(1) O Bank of England já incluiu como um de seus objetivos a proteção e consolidação da estabilidade do sistema financeiro no Reino Unido (Apostoaie; Cuza, 2010). Nesse mesmo sentido, o Banco Central Europeu, por meio do seu Mission statement, estabeleceu como um de seus objetivos salvaguardar a estabilidade financeira. No caso do Brasil, o Banco Central também pauta a estabilidade financeira como um de seus objetivos. 
encontrados na literatura terem como foco as economias desenvolvidas, como Illing e Liu (2006), Hakkio e Keeton (2009), Cardarelli et al. (2011), entre outros. Entretanto, as vulnerabilidades em torno dos fluxos de capitais em períodos financeiramente instáveis, bem como outras especificidades como a maior dependência do fluxo de capital externo, fazem das economias emergentes muito suscetíveis à presença de instabilidades financeiras. Stiglitz et al. (2006) argumentam que a volatilidade cambial nas economias emergentes, devido aos fluxos de capitais internacionais, tende a ser superior à dos mercados desenvolvidos.

Inserido neste contexto de maior importância devotada a questões inerentes à estabilidade financeira e suas implicações sobre a condução da política monetária pelo Banco Central, o presente trabalho desenvolve um Índice de Estresse Financeiro (do inglês Financial Stress Index - F.S.I.) para a economia brasileira, construído a partir de uma adaptação do índice proposto por Balakrishnan et al. (2009), a fim de identificar e caracterizar os estresses financeiros que atingiram a economia entre julho de 1999 e outubro de 2015, período este de vigência do regime de metas para inflação. Tal índice tem como base variáveis e indicadores referentes a quatro setores do mercado financeiro brasileiro, a saber: setores acionário, bancário, cambial e de dívidas externas. Baxa et al. (2013) afirmam que o uso de um indicador composto é mais realista, pois permite avaliar as instabilidades financeiras causadas por diferentes fatores, e não apenas limitar a um tipo específico de instabilidade. O trabalho relaciona, ainda, cada episódio de estresse aos principais setores do mercado financeiro que impulsionaram a sua ocorrência.

Os resultados encontrados mostraram que o F.S.I. pode ser uma ferramenta útil para o Banco Central do Brasil no contexto de identificação e caracterização de episódios que gerem estresses financeiros na economia. Foram identificados 5 episódios de estresse com duração igual ou superior a três meses, dos quais 4 estiveram associados a crises que impactaram a economia, a saber: crise de confiança, em 2002; crise financeira internacional do subprime, em 2008; crise da zona do euro, em 2011, e crise política e econômica, em 2014 e 2015. Além disso, do total de 26 episódios de estresses financeiros identificados, as instabilidades nos setores cambial e acionário potencializaram a maioria desses episódios.

A próxima seção deste trabalho discute as principais características geralmente associadas aos episódios de estresses financeiros. A metodologia e a base de dados para a construção do índice de estresse financeiro são apresentadas na seção 2. A seção 3 identifica e caracteriza os principais cenários de estresses financeiros na economia brasileira desde a adoção do regime de metas para inflação. A última seção traz as considerações finais do trabalho. 


\section{Definição e características dos estresses financeiros}

Não existe uma definição unânime por parte dos economistas para a estabilidade financeira. A divergência de definições se dá, em grande parte, em função da complexidade e dinâmica do sistema financeiro. A definição proposta por Schinasi (2004) estabelece que um sistema financeiro estável deve ser capaz de facilitar o desempenho da economia e dissipar desequilíbrios financeiros que surgem endogenamente ou que resultam de eventos adversos não antecipados. O Banco Central Europeu (ECB, 2009) sugere que a estabilidade financeira é uma condição em que o sistema financeiro é capaz de suportar choques e descobrir desequilíbrios no processo de intermediação financeira, que possam prejudicar significativamente a alocação de oportunidade de investimentos rentáveis. Parte dos economistas optam por definir o que é instabilidade financeira. De acordo com Chant (2003), a instabilidade financeira está relacionada ao cenário no qual o desempenho da economia é ameaçado ou afetado pelos mercados financeiros, isso em função do seu impacto sobre o sistema como um todo. Neste contexto, Balakrishnan et al. (2009) optam por definir o que é estresse financeiro. Segundo os autores, estresse financeiro é o período no qual o sistema financeiro está sob pressão, ou seja, as incertezas e mudanças nas expectativas sobre perda dos agentes influenciam os mercados e instituições financeiras, e sua capacidade de intermediar transações é prejudicada. Illing e Liu (2006) acrescentam que o estresse financeiro atua sobre os agentes econômicos via incerteza e mudanças nas expectativas de perdas nas instituições e mercados financeiros. O presente trabalho utiliza essa definição proposta por Balakrishnan et al. (2009) como proxy para medir as instabilidades financeiras.

Illing e Liu (2006) fornecem uma descrição sumarizada de como possíveis choques evoluem para um cenário de estresse financeiro. Segundo os autores, o estresse resulta de uma estrutura vulnerável dos sistemas financeiros somada a choques externos. Dessa forma, a fragilidade financeira descreve a fraqueza das condições financeiras e, ou, na estrutura do sistema financeiro, de modo que um choque está mais propenso a ocasionar um estresse quando as condições financeiras são fracas.

A Figura 1 exemplifica como um determinado choque pode se propagar via fragilidades nas condições financeiras (rápida redução dos fluxos de caixa, balanços de pagamentos altamente alavancados ou credores se tornam mais avessos ao risco) ou nas estruturas financeiras (falhas nas coordenações dos mercados ou fluxos de informações altamente assimétricas) e originarem estresses financeiros. 
Figura 1

$\mathrm{O}$ mecanismo do estresse financeiro

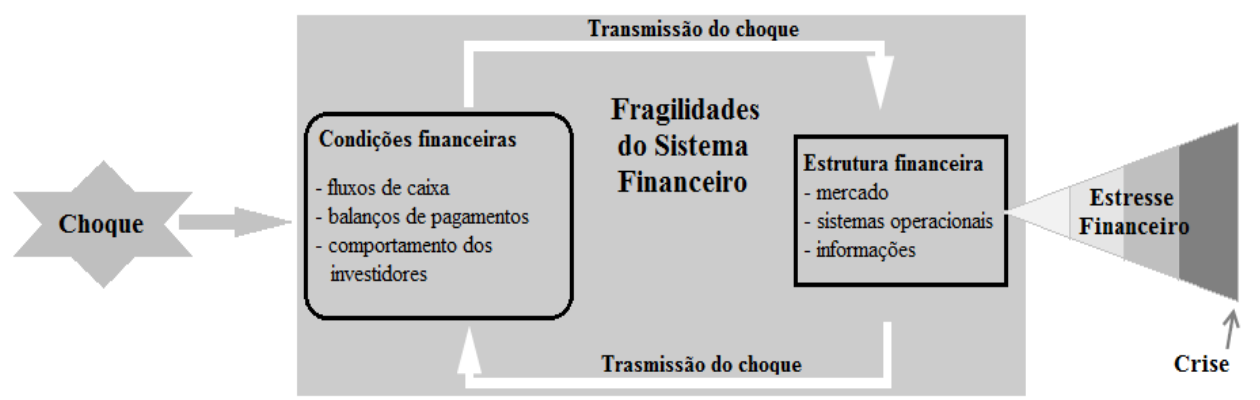

Fonte: Adaptado de Illing e Liu (2006).

Dessa forma, a magnitude dos choques e a interação das fragilidades do sistema financeiro determinam o nível de estresse, como mostrado pela Figura 1.

Alguns fenômenos podem ser associados aos cenários de estresses financeiros, conforme sugerem Hakkio e Keeton (2009), entre os quais estão: aumento da incerteza sobre o valor fundamental dos ativos ${ }^{2}$, aumento da incerteza em relação ao comportamento de outros investidores, elevação da assimetria de informação, redução da pretensão de manter ativos de risco (fuga para qualidade) e diminuição da vontade de manter ativos ilíquidos (fuga para liquidez). Cabe ressaltar que a importância relativa de tais fenômenos pode diferir de um episódio de estresse financeiro para outro, porém, cada episódio parece envolver, pelo menos, um deles, e muitas vezes todos conjuntamente.

O primeiro desses fenômenos está relacionado ao aumento da incerteza entre investidores e credores sobre os valores fundamentais dos ativos. De modo geral, tal fenômeno está ligado ao aumento da incerteza sobre as perspectivas para toda a economia ou para setores específicos. Pelo fato de ações e empréstimos refletirem em seus preços as condições econômicas futuras, o aumento da incerteza sobre as condições econômicas pode reduzir a margem de confiança de investidores e credores em relação ao valor presente de suas aplicações. Logo, a elevação da incerteza em relação ao valor fundamental converte-se em grandes volatilidades do preço de mercado desses ativos, uma vez que o investidor poderá reagir fortemente a novas informações sobre as condições econômicas futuras.

Outra incerteza que geralmente se eleva durante crises financeiras, destacada por Hakkio e Keeton (2009), diz respeito ao comportamento de outros investidores. Quando os investidores baseiam suas decisões em expectativas futuras sobre as ações

(2) Definido como o valor presente dos fluxos de caixa futuros, como taxa de juros e dividendos (Hakkio; Keeton, 2009). 
de outros investidores, os preços dos ativos financeiros tendem a se desalinhar dos devidos valores fundamentais e, portanto, se tornarem mais voláteis.

Em relação à assimetria de informação, os autores ressaltam que os problemas de risco moral e seleção adversa podem interferir nos preços dos ativos e empréstimos. A assimetria de informação é potencialmente mais perigosa durante crises financeiras por dois motivos: i) a variação em relação à qualidade dos ativos e empréstimos pode aumentar substancialmente e; ii) a perda de confiança dos credores nas informações relacionadas aos tomadores de empréstimos.

Os dois últimos fenômenos presentes durante crises são a redução na disponibilidade em manter ativos de risco e de baixa liquidez. O primeiro deles incorre no movimento de fuga para qualidade tomado pelo investidor. Assim, a mudança nas preferências dos investidores exige um maior retorno dos ativos de risco em relação aos considerados de baixo risco, fato que contribui para ampliar a taxa de diferencial de retorno entre esses dois tipos de ativos. Por fim, durante períodos de instabilidades financeiras, investidores têm menor interesse em manter ativos ilíquidos, optando pela liquidez e, consequentemente, na fuga para liquidez. O fato de um ativo não apresentar liquidez está relacionado com a incerteza de seu detentor no momento da venda do ativo, seja a venda por motivo súbito de necessidade de dinheiro ou por algum caso inesperado não poder inferir se o respectivo preço do ativo está próximo do seu valor fundamental. Há casos em que a baixa liquidez se dá pelo fato do mercado para um determinado ativo ser pequeno, de modo que operações de compra e venda impactarão fortemente os preços.

Cabe assinalar um sexto fenômeno, ligado à pressão no setor de câmbio, presente nos períodos de estresses financeiros. Stiglitz et al. (2006) argumentam que a volatilidade cambial nas economias emergentes, devido aos fluxos de capitais internacionais, tende a ser superior à dos mercados desenvolvidos. Ainda, Akyüz e Cornford (1999) alertam para os efeitos mais significativos entre os mercados financeiros das economias emergentes diante dos fluxos de capitais potencialmente instabilizadores em momentos de instabilidades econômicas. Portanto, a dependência e a elevada participação de capitais externos nos sistemas financeiros das economias emergentes, como é o caso do Brasil, geram grande volatilidade e pressão nas moedas nacionais em momentos de crises financeiras devido à saída de capitais dessas economias em direção a economias mais seguras.

\section{Construção do indicador de estresse financeiro (F.S.I.)}

Devido à complexidade do sistema financeiro, um índice de estresse financeiro não deve ter como foco específico apenas um setor/segmento, mas fornecer uma análise mais ampla do sistema como um todo. Neste contexto, Cardarelli et al. (2011) salientam que qualquer caracterização de episódios de estresse financeiro deve levar em consideração as condições do setor bancário, o 
estado da intermediação não bancária através dos preços das ações e dívidas (bonds), além do comportamento do setor cambial.

Dessa forma, o presente trabalho adapta o indicador proposto por Balakrishnan et al. (2009), que desenvolveram um índice de estresse financeiro para economias emergentes. Tal índice é semelhante ao proposto por Cardarelli et al. (2011), porém, difere por incluir a mensuração de pressões do setor cambial, sendo essa última uma fonte de estresse comum em economias emergentes ${ }^{3}$.

Em síntese, o F.S.I. utilizado no presente trabalho engloba seis componentes referentes a quatro setores do mercado financeiro, sendo um componente referente ao setor bancário, dois relacionados ao setor acionário, dois referentes ao setor cambial e um inerente ao setor de dívidas externas. De maneira geral, Balakrishnan et al. (2009) ressaltam que o índice de estresse financeiro busca mensurar cenários de estresses relacionados com as seguintes características fundamentais: i) grandes oscilações nos preços dos ativos; ii) elevação abrupta do risco ou incerteza; iii) restrição da liquidez e; iv) saúde do sistema bancário.

\subsection{Setor Bancário}

O setor bancário engloba o componente "beta do setor bancário". Esse componente busca mensurar os episódios de estresses financeiros decorrentes de crises bancárias. Segundo Illing e Liu (2006), a maioria dos estudos que analisam crises bancárias tem como base informações qualitativas, devido à insuficiência de dados apropriados para a análise. Os autores argumentam ainda que as variáveis comumente utilizadas em crises ou estresses bancários, como lucros dos bancos, crescimento do crédito ou créditos de liquidação duvidosa, são altamente prócíclicas, enquanto que os preços de ações bancárias tendem a ser correlacionados com o mercado de ações em geral.

Um método quantitativo que tem sido empregado em trabalhos recentes que analisam crises bancárias (Illing; Liu, 2006; Park; Mercado Jr., 2014) foca-se na utilização da razão entre os preços das ações dos bancos e o preço total das ações do mercado financeiro. Dessa forma, o "beta" do setor bancário utilizado no presente trabalho é definido como:

$$
\beta_{t}=\frac{\operatorname{COV}\left(r_{t}^{M}, r_{t}^{B}\right)}{\sigma_{M}^{2}}
$$

em que: $\beta_{t}$ é a razão entre a covariância $(C O V)$ entre os retornos do setor bancário $\left(r^{B}\right)$, representado pelas médias dos retornos das ações dos seguintes bancos: Brasil (BBAS3), Itaú (ITSA4), Itaú-Unibanco (ITUB3 e ITUB4), Bradesco (BBDC3 e BBDC4) e Santander

(3) O índice original proposto por Balakrishnan et al. (2009) engloba cinco componentes. O presente trabalho inclui no F.S.I. um componente relacionado à volatilidade do mercado cambial, como será mostrado posteriormente. 
(SANB11), negociadas na BM\&FBovespa, e os retornos do setor de ações em geral $\left(r^{M}\right)$, indicado pelo Índice Bovespa (Ibovespa), e a variância dos retornos do setor acionário $\left(\sigma_{M}^{2}\right)^{4}$. O Ibovespa é utilizado como proxy para o mercado acionário como um todo por ser o indicador do desempenho médio das cotações dos ativos de maior negociabilidade e representatividade do mercado de ações brasileiro (BM\&FBovespa, 2015) ${ }^{5}$. São considerados os retornos diários das ações dos bancos e do Ibovespa para o cálculo da covariância e variância na equação (1). Para obter os valores mensais do "beta" para compor o F.S.I., recorre-se à média aritmética das observações diárias.

A covariância e a variância, inseridas na equação (1), são estimadas através de modelos GARCH (General Autoregressive Conditional Heteroscedasticity) multivariados. Trata-se de uma inovação do presente trabalho, que permitirá mensurar de modo mais preciso os episódios marcados por crises bancárias ${ }^{6}$. A utilização de modelos de volatilidade multivariados, como é o caso do GARCH multivariado, permite estudar o padrão das variâncias e covariâncias ao longo do tempo, sem a perda ou generalização de informações. Laurent (2009) afirma que o estudo das relações entre duas séries financeiras por meio de uma modelagem multivariada resulta em modelos empíricos mais relevantes em relação aos modelos univariados.

Tais modelos multivariados que buscaram analisar o processo de volatilidade variantes no tempo foram desenvolvidos inicialmente na década 1980 e primeira metade da década de 1990. De acordo com Tsay (2010), o estudo das volatilidades em um contexto multivariado tem importantes aplicações financeiras como precificação de ativos e opções, seleção de portfólio e gestão de risco, entre outras $^{7}$. Entretanto, é nos estudos das relações das volatilidades e co-volatilidades entre os mercados, que os modelos GARCH multivariados têm merecido maior atenção nos últimos anos.

A especificação do modelo multivariado utilizado no presente trabalho foi desenvolvida por Engle e Kroner (1995), conhecida na literatura por modelo BabaEngle-Kraft-Kroner - BEKK.

A especificação do modelo GARCH-BEKK é dada por:

$$
H_{t}=C^{\prime} C+\sum_{k=1}^{K} A_{k}^{\prime} \varepsilon_{t-k} \varepsilon_{t-k}^{\prime} A_{k}+\sum_{k=1}^{K} B_{k}^{\prime} H_{t-k} B_{k}
$$

(4) As ações bancárias selecionadas possuem elevada participação na composição do Índice Financeiro (IFNC), elaborado e divulgado diariamente pela BM\&Fbovespa.

(5) O Ibovespa é composto por ações de diversos setores de atuação do mercado como construção e transporte, financeiro, petróleo, gás e biocombustível, telecomunicação e consumo cíclico, entre outros.

(6) Os estudos de Balakrishnan et al. (2009), Cardarelli et al. (2011) e Illing e Liu (2006) calculam o beta do setor bancário com base na covariância simples entre os retornos no período de 12 meses.

(7) Para mais aplicações dos modelos GARCH multivariados em diversas áreas da economia, ver Bauwens et al. (2006). 
em que $H_{t}$ é uma matriz de covariância $N x N$, entre os retornos dos preços das ações do setor bancário e acionário, definida positiva e mensurável em relação ao conjunto de informações no tempo $t$ - 1 . Os resíduos do vetor de correção de erros ou vetor de inovação são dados por $\varepsilon_{t}, C$ é uma matriz triangular inferior, $A_{k}$ e $B_{k}$ são matrizes de parâmetros $N \times N$. A decomposição do termo constante, $C$, em um produto de duas matrizes triangulares garante que $H_{t}$ seja positivo.

A equação (3) pode ser decomposta em:

$$
\begin{gathered}
{\left[\begin{array}{ll}
h_{11, t} & h_{1 j, t} \\
h_{j 1, t} & h_{22, t}
\end{array}\right]=\left[\begin{array}{cc}
C_{11} & C_{21} \\
0 & C_{22}
\end{array}\right] x\left[\begin{array}{ll}
C_{11} & 0 \\
C_{21} & C_{22}
\end{array}\right]+} \\
{\left[\begin{array}{ll}
A_{11,1} & A_{21,1} \\
A_{12,1} & A_{22,1}
\end{array}\right] x\left[\begin{array}{cc}
\varepsilon_{1, t-1}^{2} & \varepsilon_{1, t-1} \varepsilon_{2, t-1} \\
\varepsilon_{2, t-1} \varepsilon_{1, t-1} & \varepsilon_{2, t-1}^{2}
\end{array}\right] x\left[\begin{array}{ll}
A_{11,1} & A_{12,1} \\
A_{21,1} & A_{22,1}
\end{array}\right]+} \\
{\left[\begin{array}{ll}
B_{11,1} & B_{21,1} \\
B_{12,1} & B_{22,1}
\end{array}\right] x\left[\begin{array}{ll}
h_{11, t-1} & h_{12, t-1} \\
h_{21, t-1} & h_{22, t-1}
\end{array}\right] x\left[\begin{array}{ll}
B_{11,1} & B_{12,1} \\
B_{21,1} & B_{22,1}
\end{array}\right]}
\end{gathered}
$$

Em relação à equação (1), quando o beta é maior que 1, a volatilidade dos retornos das ações bancárias é maior que a volatilidade dos retornos totais do mercado global, o que sugere que o setor bancário é relativamente mais arriscado, uma vez que há uma relação direta entre risco e retorno.

\subsection{Setor acionário}

Os dois componentes do F.S.I., a seguir, trazem informações referentes ao setor acionário. Segundo Illing e Liu (2006), quedas nos índices acionários podem ser indicativos de grandes perdas futuras, maiores riscos ou aumento da incerteza em relação à lucratividade das empresas. O primeiro desses componentes é o retorno do setor acionário. Para a construção desse componente é necessária a escolha de um índice que expresse as condições gerais do setor a ser analisado. O presente trabalho utiliza o Índice IBovespa por ser considerado o mais importante indicador do desempenho médio das cotações do mercado de ações brasileiro, ao medir o comportamento dos principais papéis negociados na BM\&FBovespa. Os retornos no setor acionário são medidos como:

$$
r_{t}=\ln \left(\frac{p_{t}}{p_{t-1}}\right)
$$

em que $p_{t}$ e $p_{t-1}$ são os valores do IBovespa no período $t$ e $t$ - 1 , respectivamente. Dessa forma, de acordo com o procedimento adotado por Cardarelli et al. (2011), para que a queda nos preços das ações represente a elevação do índice de estresse financeiro, toda a série de retornos dada por (4) é multiplicada por -1. Tal procedimento busca associar movimentos de saídas de capitais por motivos de 
segurança ou liquidez, entre outros, a episódios de estresses financeiros ${ }^{8}$. As observações referentes ao IBovespa são de periodicidade diária. Para a agregação no F.S.I., os retornos mensais foram obtidos através da média aritmética dos retornos diários.

Outro componente do F.S.I. relacionado ao setor de ações é a volatilidade do setor acionário brasileiro. Como ressaltado por Cardarelli et al. (2011), a presença de clusters de volatilidade é uma característica em muitos preços de ativos financeiros, especialmente quando o mercado financeiro se encontra em estado de incerteza.

A volatilidade no índice IBovespa é mensurada através da especificação dos modelos GARCH univariados, sendo essa técnica de estimação bastante difundida em trabalhos que analisam questões inerentes às instabilidades financeiras (Illing; Liu, 2006; Balakrishnan et al., 2009; Silva et al., 2012; Cardarelli et al., 2011) $9^{9}$. Dessa forma, a volatilidade segue o modelo GARCH $(\mathrm{p}, \mathrm{q})$ dado por:

$$
\sigma_{t}^{2}=\omega+\sum_{i=1}^{p} \alpha_{i} \varepsilon_{t-i}^{2}+\sum_{j=1}^{q} \gamma_{j} \sigma_{t-j}^{2}
$$

em que: $\sigma_{t}^{2}$ é a variância do IBovespa, e $\varepsilon$ é o termo de erro da equação da média dos retornos, dada por:

$$
z_{t}=\alpha+\varepsilon_{t}
$$

em que $z_{t}$ é o retorno do IBovespa no período $t$.

No presente trabalho, a volatilidade do setor acionário é modelada a partir de um GARCH de ordem $(3,3)^{10}$. Convém ressaltar que, assim como o caso do componente do retorno visto anteriormente, por se tratar de dados diários, utiliza-se a média aritmética das observações diárias a fim de se obter as volatilidades mensais para composição do F.S.I.

(8) Retornos negativos tendem a estar associados a movimentos de fuga de capitais para mercados mais seguros e líquidos, de modo a ocasionar estresses financeiros.

(9) São testadas diferentes especificações do modelo GARCH original a fim de verificar a existência de choques diferenciados nas séries de retornos, caso dos modelos EGARCH e TARCH. Porém, o padrão da variância condicional estimada pelos modelos em questão não se altera significativamente daquela estimada pelo GARCH tradicional. Nesse sentido, devido à alta correlação apresentada entre a variância condicional estimada pela especificação original e pelos modelos TARCH $(0,96)$ e EGARCH $(0,93)$, opta-se pelo uso do modelo GARCH tradicional. A Figura A.1, no Apêndice, traz as variâncias condicionais estimadas pelos modelos em questão.

(10) Para a definição da ordem do modelo GARCH, adota-se o procedimento seguido por Tsay (2010), o qual busca selecionar a ordem de maneira mais parcimoniosa possível, e, posteriormente, verifica-se a presença de correlação serial e efeito ARCH nos resíduos. Desse modo, o modelo GARCH $(3,3)$ obtém sucesso em modelar a volatilidade dos retornos do mercado acionário, uma vez que os resíduos do modelo não apresentam correlação serial e efeito ARCH. 


\subsection{Setor cambial}

Outro segmento abarcado pelo F.S.I. é o setor cambial, que é mensurado a partir do índice de pressão do mercado cambial (do inglês Exchange Market Pressure Index - EMPI) e da volatilidade da taxa de câmbio. Em relação ao primeiro componente, EMPI, Park e Mercado Jr (2014) argumentam que crises cambiais são definidas como períodos de significantes desvalorizações da moeda e/ou perdas de reservas cambiais $^{11}$. Dessa forma, o EMPI busca capturar esses dois efeitos conjuntamente, sendo definido como:

$$
E M P I_{t}=\frac{\left(\Delta e_{t}-\mu_{\Delta e}\right)}{\sigma_{\Delta e}}-\frac{\left(\Delta R E S_{t}-\mu_{\Delta R E S}\right)}{\sigma_{\triangle R E S}}
$$

em que: $\Delta e$ e $\triangle R E S$ são variações percentuais mensais na taxa de câmbio nominal (R\$/US\$) e no total de reservas, respectivamente; $\mu$ e $\sigma$ indicam a média e o desvio padrão de cada uma das séries, respectivamente.

O segundo componente relacionado ao setor cambial se refere à volatilidade da taxa de câmbio nominal, sendo essa mensurada com base na especificação dos modelos GARCH, de modo semelhante ao apresentado pelas equações (3) e (4). Nesse caso, são consideradas as variações diárias da taxa de câmbio (venda) para o cálculo da volatilidade diária. Em seguida, para compor o F.S.I., calcula-se a média aritmética das volatilidades diárias para se obter a volatilidade mensal da taxa de câmbio. Cabe ressaltar que a inclusão deste componente é outra inovação do presente trabalho, sendo relevante a sua inclusão pelo fato da economia brasileira apresentar grande volatilidade cambial, fato característico de grande parte das economias emergentes, em virtude do fluxo de capitais internacionais nessas economias, como sugerido por Stiglitz et al. (2006).

\subsection{Setor de dívidas}

O último segmento incluído no F.S.I. está relacionado ao setor de dívidas externas do governo. A incapacidade dos governos em cumprir suas obrigações (dívidas) pode gerar estresses financeiros nos países em débito. De acordo com Illing e Liu (2006), grande parte da literatura relacionada às crises da dívida diz respeito a um grupo de economias emergentes expostas ao elevado endividamento externo na década de 1980. Tal fato corrobora a importância de se analisar esse componente como potencial causa de estresses financeiros na economia brasileira.

Seguindo o consenso na literatura, os estresses financeiros no setor de dívidas externas do governo são expressos pelo spread entre o retorno da dívida

(11) A utilização do EMPI como forma de captar os estresses financeiros oriundos do setor cambial é encontrado em diversos trabalhos que analisam índices de estresses financeiros (Balakrishnan et al., 2009; Cardarelli et al., 2011; Park; Mercado Jr., 2014). 
externa brasileira e o retorno sobre títulos do governo dos Estados Unidos (Sy, 2004; Das et al., 2005; Park; Mercado Jr., 2014). Desse modo, o setor de dívidas considerado neste trabalho é medido pelo índice EMBI Brasil + , que corresponde à média ponderada dos prêmios pagos por títulos da dívida externa brasileira em relação a papéis de prazo equivalente do Tesouro dos Estados Unidos, que são considerados livres de risco. A unidade de medida do índice é o ponto-base, que mostra a diferença entre a taxa de retorno dos títulos brasileiros e a oferecida por títulos emitidos pelo Tesouro americano.

Os valores do EMBI Brasil + aumentarão se as expectativas de perdas futuras de aplicações em títulos da dívida pública brasileira aumentarem, ou se uma maior incerteza quanto à rentabilidade desses títulos levar a uma menor confiança, o que implica uma maior probabilidade de perda. Dessa forma, ambos os fatores são indicativos de estresses.

\subsection{Agregação dos componentes e identificação dos episódios de estresses financeiros}

Uma vez apresentados os componentes do índice de estresse financeiro, F.S.I., parte-se para a exposição de como esses componentes são agregados. A escolha do método de ponderação é um dos elementos mais relevantes na construção de um índice financeiro, assim como a escolha das variáveis.

Em relação aos métodos de agregação, Balaskrishnan et al. (2009) argumentam que o índice agregado ideal seria aquele construído utilizando ponderações econômicas, como o tamanho de cada setor do setor financeiro analisado $^{12}$. Entretanto, não há consenso em relação a tais participações ou proporções, o que inviabiliza a maioria dos estudos. Dessa forma, o presente trabalho faz uso do método de ponderação baseado na igualdade de variâncias.

O método de igualdade de variância permite a criação de um índice de estresse financeiro que atribui igual importância a cada componente. Como ressaltado por Illing e Liu (2006), esse método é muito utilizado na literatura (Balakrishnan et al., 2009; Cardarelli et al., 2011; Park; Mercado JR., 2014), além de ter sido adotado no estudo do Fundo Monetário Internacional que investigou a ocorrência de estresses financeiros em 17 países desenvolvidos (IMF, 2008). Além disso, o estudo de Illing e Liu (2006) comparou a robustez de quatro abordagens diferentes de ponderações (Análise Fatorial, Ponderação por crédito, Igualdade de Variância e Ponderações usando Funções de Distribuição Cumulativa). Os resultados mostraram que o método de igualdade de variância apresentou alta capacidade em identificar os episódios de estresses financeiros para o Canadá.

(12) Um exemplo seria o método de ponderação de créditos que baseia-se no tamanho relativo de cada mercado, de modo que quanto maior a proporção de crédito nesse mercado em relação ao crédito total da economia, maior o peso associado a essa variável ou componente. 
O método utilizado no presente trabalho consiste em subtrair cada observação dos componentes pela respectiva média, e então dividir pelo desviopadrão. Tal procedimento, apresentado pela equação a seguir, consiste na padronização de cada um dos componentes, daí o termo "igualdade de variância". ${ }^{13}$

$$
k_{i t}=\frac{\left(x_{i t}-\bar{x}_{i}\right)}{\sigma_{i}}
$$

em que: $k_{i t}$ é o componente padronizado da variável $i ; \bar{x}_{i}$ é a média da variável $i ; \sigma_{i}$ é o desvio-padrão da variável $i$, e; o subscrito $i$ se refere aos componentes: Beta do setor bancário, retorno do IBovespa, volatilidade do IBovespa, EMBI Brasil +, EMPI e volatilidade cambial.

Portanto, a partir dos seis componentes padronizados, o índice de estresse financeiro para a economia brasileira é dado por:

$$
F . S . I .=\beta+\text { ret.IBOV }+ \text { volat. } I B O V+E M B I+E M P I+\text { volat. cambial (9) }
$$

em que: F.S.I. é o Índice de Estresse Financeiro para a economia brasileira, $\beta$ é beta do setor bancário, ret.IBOV é o retorno do IBovespa, volat.IBOV é a volatilidade do IBovespa, EMBI é o índice EMBI BRASIL +, EMPI é o Índice de Pressão do Mercado Cambial e volat.cambial é a volatilidade da taxa de câmbio nominal.

Por fim, cabe ressaltar o modo de identificação dos episódios de estresses financeiros analisados no estudo. $O$ presente trabalho segue o método proposto por Cardarelli et al. (2011), segundo o qual os episódios de estresses financeiros são definidos como períodos nos quais o índice é maior que um desvio-padrão acima da tendência, sendo essa última identificada através do uso do filtro Hodrick-Prescott $(\mathrm{HP})^{14}$. Pelo fato de o F.S.I. ser de periodicidade mensal, o valor do parâmetro de suavização $(\lambda)$ foi definido em $14.400^{15}$. Esses episódios sinalizam mudanças

(13) A padronização retira as unidades de medidas das variáveis. Assim, valores negativos do I.F.S. correspondem a períodos nos quais a maioria dos indicadores que compõem o índice apresentou valores abaixo das respectivas médias, e vice-versa.

(14) Trata-se de um método de suavização de série que permite obter a estimativa suavizada do componente de tendência no longo prazo. Dessa forma, dado o constante desenvolvimento dos sistemas financeiros, tal uso está em conformidade com o fato de o estresse financeiro poder se manifestar através de diferentes formas ao longo do tempo, conforme justificado por Cardarelli et al. (2011). Para mais detalhes sobre o filtro HP, ver Hodrick e Prescott (1997).

(15) O valor apropriado para o parâmetro de suavização depende da periodicidade da base de dados. A sugestão dada pela literatura é utilizar os valores de 100, 1600 e 14400 para dados com periodicidades anuais, trimestrais e mensais, respectivamente, sendo, portanto, esses valores usados em artigos e como padrões em softwares (IMF, 2007; Chakraborty, 2016; Mathworks, 2016). A fim de comparação, utiliza-se o valor de 1.600 para o parâmetro de suavização, sendo que a identificação dos episódios de estresse financeiros não sofre alteração. 
abruptas nos valores dos componentes relacionados ao setor bancário, acionário, cambial e, ou, de dívidas, individualmente ou em conjunto.

Para classificar se um episódio de estresse financeiro foi impulsionado principalmente pelo setor bancário, acionário, cambial ou de dívidas, foi analisada a alteração no F.S.I. do mês anterior ao início do episódio até o valor máximo do índice dentro do episódio. Dessa forma, se a maior parte do aumento no F.S.I. foi devido aos componentes do setor acionário, então o episódio de estresse é atribuído a este setor, sendo a mesma regra aplicada para os demais. Adicionalmente, devido à complexidade dos sistemas financeiros, nos quais há uma forte inter-relação entre os setores, é possível identificar setores secundários que contribuem para a elevação do estresse financeiro. Assim, se os componentes do setor cambial contribuírem com pelo menos $20 \%$ da elevação no F.S.I., então o episódio é também relacionado a este setor, sendo esta regra adotada para análise nos outros setores ${ }^{16}$.

\subsection{Descrição e fontes dos dados}

O Índice BOVESPA, utilizado no componente "beta" do setor bancário e na volatilidade do setor de ações, é uma proxy para o setor acionário como um todo, sendo composto por ações que representam mais de $80 \%$ do número de negócios e volume financeiros na bolsa de valores brasileira. As ações presentes no IBovespa são de empresas de diversos setores de atuação do mercado, como construção e transporte, financeiro, petróleo, gás e biocombustível, telecomunicação e consumo cíclico, entre outros. As ações bancárias que fazem parte do componente "beta" do setor bancário englobam os seguintes papéis: ações ordinárias $(\mathrm{ON})$ e preferenciais (PN) do Banco Bradesco, cujo código de negociação é BBDC3 e BBDC4, respectivamente; ações ON e PN do Banco Itaú-Unibanco, sendo expressas pelos códigos ITUB3 e ITUB4, respectivamente; ações ON do Banco do Brasil (BBAS3); ações PN do Banco Itaú (ITSA4) e um pacote de ações (UNT) do Banco Santander (SANB11) composto por ações ON e PN do respectivo banco. Tanto o índice IBovespa, quanto as ações bancárias, são disponibilizados pela bolsa de valores BM\&FBovespa com periodicidade diária, sendo coletados entre os dias 01/07/1999 e $30 / 10 / 2015^{17}$.

Em relação aos componentes do setor cambial, o índice de pressão cambial (EMPI) é composto por séries mensais obtidas no Banco Central do Brasil. São utilizadas a taxa de câmbio nominal (R \$US\$) para venda, expressa pela série 3698, e as reservas internacionais, expressas em milhões de US\$, divulgadas pela série

(16) A definição do percentual para a classificação dos setores relacionados ao episódio de estresse financeiro foi baseada em Cardarelli et al. (2011), porém diferencia-se da proposta original por incluir um mercado adicional na análise.

(17) As ações dos bancos Itaú-Unibanco (ITUB3 e ITUB4) e Santander (SANB11) começaram a ser negociadas na BM\&FBovespa em 21/05/2009 e 08/10/2009, respectivamente, sendo coletadas a partir dessas datas. 
3546. O componente relacionado à volatilidade do setor cambial também faz uso da taxa de câmbio nominal (R \$/US\$) para venda. Porém, sua periodicidade é diária, sendo expressa pela série 001, disponibilizada pelo Banco Central do Brasil.

Por último, a série EMBI BRASIL +, utilizada na análise do componente de dívidas, é diária e fornecida pela J.P. Morgan. O EMBI+ foi criado para classificar somente países que apresentassem alto nível de risco segundo as agências de rating e que tivessem emitido títulos de valor mínimo de US\$ 500 milhões, com prazo de ao menos 2,5 anos.

\section{Análise dos estresses financeiros na economia brasileira ao longo do regime de metas para inflação}

O presente trabalho deriva uma estimativa ordinal dos estresses financeiros sob a forma de um índice, o Índice de Estresse Financeiro (F.S.I.). Trata-se de um índice com base em Balakrishnan et al. (2009), porém com algumas inovações, com o intuito de identificar e caracterizar os episódios de estresses financeiros que incidiram sobre a economia brasileira no período posterior à adoção do regime de metas para inflação.

O Quadro 1 sumariza os seis componentes do F.S.I. construídos para a economia brasileira e relaciona cada componente ao aspecto do estresse financeiro que ele representa. $\mathrm{O}$ quadro também fornece o valor médio e o desvio-padrão das séries antes da padronização de cada componente.

Quadro 1

Variáveis incluídas no Índice de Estresse Financeiro

\begin{tabular}{|c|c|c|c|}
\hline Variáveis & $\begin{array}{l}\text { Aspecto do estresse financeiro } \\
\text { representado pela variável }\end{array}$ & $\begin{array}{c}\text { Média } \\
\text { (julho/1999 a } \\
\text { outubro/2015) }\end{array}$ & $\begin{array}{l}\text { Desvio-padrão } \\
\text { (julho/1999 a } \\
\text { outubro/2015) }\end{array}$ \\
\hline $\begin{array}{l}\text { Beta do setor } \\
\text { bancário }\end{array}$ & $\begin{array}{l}\text { Incerteza sobre o valor fundamental } \\
\text { dos ativos financeiros e sobre o } \\
\text { comportamento de outros investidores; } \\
\text { assimetria de informação. }\end{array}$ & 0,653 & 0,071 \\
\hline Retorno do IBovespa & $\begin{array}{c}\text { Incerteza sobre o valor fundamental } \\
\text { dos ativos financeiros e sobre o } \\
\text { comportamento de outros investidores. }\end{array}$ & $-0,0003$ & 0,003 \\
\hline $\begin{array}{l}\text { Volatilidade do } \\
\text { IBovespa }\end{array}$ & Fuga para qualidade e liquidez. & 0,0003 & 0,0002 \\
\hline $\begin{array}{c}\text { Índice de Pressão } \\
\text { Cambial }\end{array}$ & $\begin{array}{l}\text { Fuga para qualidade e liquidez; } \\
\text { pressão cambial. }\end{array}$ & 0,0001 & 1,517 \\
\hline $\begin{array}{l}\text { Volatilidade da taxa } \\
\text { de câmbio }(R \$ / U S \$)\end{array}$ & $\begin{array}{l}\text { Fuga para qualidade e liquidez; } \\
\text { pressão cambial. }\end{array}$ & 0,00001 & 0,0001 \\
\hline$E M B I+$ Brasil & $\begin{array}{l}\text { Assimetria de informação; fuga para } \\
\text { qualidade e liquidez. }\end{array}$ & 462,03 & 372,194 \\
\hline
\end{tabular}

Fonte: Resultados da pesquisa. 
Uma vez relacionados os componentes do F.S.I. às características do estresse que eles estão associados, apresenta-se, na Figura 2, o Índice de Estresse Financeiro para o Brasil ao longo da adoção do regime de metas para inflação. Os episódios estão divididos em dois grupos, de acordo com a duração do estresse financeiro na economia. As áreas sombreadas mais claras se referem aos períodos de estresses financeiros mais curtos, cujos impactos se deram em um ou dois meses, enquanto que as áreas mais escuras estão relacionadas aos episódios com duração igual ou superior a três meses.

Figura 2

Índice de Estresse Financeiro para o Brasil, julho/1999 a outubro/2015

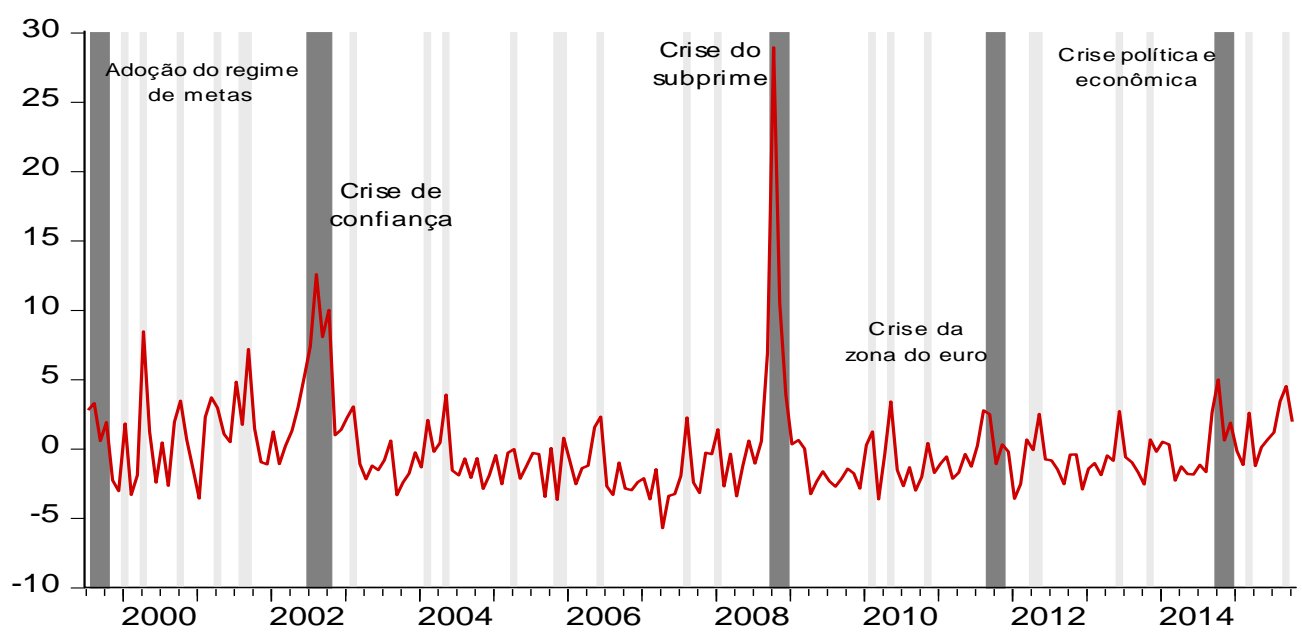

Fonte: Resultados da pesquisa.

De modo geral, foram identificados 26 episódios de estresses financeiros na economia brasileira, entre julho de 1999 e outubro de 2015. Desses episódios, 5 tiveram duração igual ou superior a 3 meses, sendo possível associá-los a períodos de crises de origem interna ou externa que impactaram a economia brasileira. $\mathrm{O}$ mais expressivo episódio de estresse foi o ocasionado pela crise do subprime, em meados de 2008, em virtude das hipotecas subprimes no mercado norte-americano. Pode-se ressaltar ainda a crise de confiança, em meados de 2002, decorrente da sucessão presidencial no Brasil, bem como a recente crise política e econômica.

Uma síntese dos períodos de estresses financeiros identificados a partir dos valores referentes ao F.S.I. para a economia brasileira, no período de julho de 1999 a outubro de 2015, é apresentada na Tabela 1. Os episódios de estresse financeiro foram relacionados a cada um dos setores analisados de acordo com as contribuições desses setores para a elevação do F.S.I. 
Tabela 1

Episódios de estresses financeiros no Brasil, julho/1999 a outubro/2015

\begin{tabular}{|c|c|c|c|c|c|c|c|c|c|c|c|c|c|c|c|c|c|c|}
\hline \multicolumn{2}{|l|}{ Total } & よे & 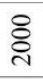 & চ̊ & ฮิ & $\stackrel{\overbrace{}}{8}$ & ঠ্ণ & $\stackrel{\overbrace{}}{ి}$ & ๕ & 호 & 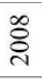 & 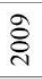 & $\stackrel{\circ}{\circ}$ & $\bar{\Xi}$ & 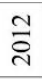 & $\stackrel{m}{\check{2}}$ & 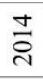 & in \\
\hline $\begin{array}{c}\text { Estresse } \\
\text { financeiro }\end{array}$ & 26 & 1 & 3 & 2 & 1 & 1 & 2 & 2 & 1 & 1 & 2 & - & 3 & 1 & 1 & 2 & 1 & 2 \\
\hline \multicolumn{19}{|c|}{ Principal setor: } \\
\hline Bancário & 5 & - & 1 & 1 & - & - & 1 & 1 & - & - & - & - & 1 & - & - & - & - & - \\
\hline Acionário & 7 & - & 1 & 1 & - & - & - & - & 1 & - & 1 & - & - & - & - & 1 & 1 & 1 \\
\hline Cambial & 13 & - & 1 & - & 1 & 1 & 1 & 1 & - & 1 & 1 & - & 2 & 1 & 1 & 1 & - & 1 \\
\hline Dívidas & 1 & 1 & - & - & - & - & - & - & - & - & - & - & - & - & - & - & - & - \\
\hline \multicolumn{19}{|c|}{ Elevação secundária: } \\
\hline Bancário & 8 & - & 2 & 1 & - & - & - & - & - & - & 1 & - & 1 & - & - & 1 & 1 & 1 \\
\hline Acionário & 13 & - & 1 & - & 1 & 1 & 1 & 2 & - & - & 1 & - & 2 & 1 & 1 & 1 & - & 1 \\
\hline Cambial & 8 & 1 & 1 & 2 & - & - & 1 & - & - & - & - & - & 1 & - & - & 1 & - & 1 \\
\hline Dívidas & 1 & - & - & - & 1 & - & - & - & - & - & - & - & - & - & - & - & - & - \\
\hline
\end{tabular}

* O ano de 2015 inclui os meses de janeiro a outubro.

Fonte: Resultados da Pesquisa.

Dos 26 episódios de estresses financeiros, 13 foram impulsionados principalmente por estresses no setor cambial, ou seja, a volatilidade e a pressão sobre a taxa de câmbio representaram grande parcela do aumento no F.S.I. durante estes episódios. Neste contexto, as pressões no setor cambial foram recorrentes durante os anos que se seguiram após o abandono da âncora cambial, ocorrida em janeiro de 1999, e intensificados com a consolidação do regime de metas na economia brasileira. Tal fato evidencia a continuidade das pressões sobre o Real, iniciadas anos antes do fim da âncora cambial, e que levaram à adoção do regime de câmbio flutuante, além de corroborar a maior vulnerabilidade da economia frente aos fluxos de capitais em cenários economicamente instáveis.

Outro setor de relevante importância para a elevação do F.S.I. foi o acionário. Os componentes do setor acionário foram os principais responsáveis pela elevação do estresse financeiro em 7 episódios, dos quais 4 ocorreram a partir da crise do subprime americano, nos anos de 2007 e 2008, contribuindo, assim, fortemente para os episódios recentes de estresses financeiros na economia brasileira. O setor bancário impulsionou 5 períodos de estresses financeiros, dos quais quatro ocorreram entre os anos de 1999 e 2005.

Devido à complexidade e inter-relação existente entre os diversos setores que compõem um sistema financeiro, é comum que estresses iniciados em um determinado setor ou segmento sejam refletidos em outros setores do sistema financeiro. Assim, dos 13 episódios que refletiram principalmente estresses no setor cambial, em 12 deles as variáveis do setor de ações representaram $20 \%$ ou mais da elevação no F.S.I. A intensa relação dos setores cambial e acionário ratifica o fato, já elucidado, da maior vulnerabilidade da economia brasileira frente aos fluxos de 
capitais externos, impactando diretamente a bolsa de valores e, consequentemente, a taxa de câmbio.

A fim de analisar as particularidades inerentes a cada um dos episódios de estresses identificados nas últimas décadas na economia brasileira, bem como associá-los às crises que incidiram sobre a economia como um todo, a Figura 3 mostra a participação de cada um dos 4 setores analisados no valor final do F.S.I. .

Inicialmente, são analisados os episódios de estresses financeiros com maior duração, representados pelas áreas sombreadas mais escuras na Figura 3. Desse modo, foram identificados 5 episódios de estresses financeiros com duração igual ou superior a três meses.

Figura 3

Participação dos setores acionário, bancário, cambial e de dívidas no Índice de Estresse Financeiro para o Brasil, julho/1999 a outubro/2015

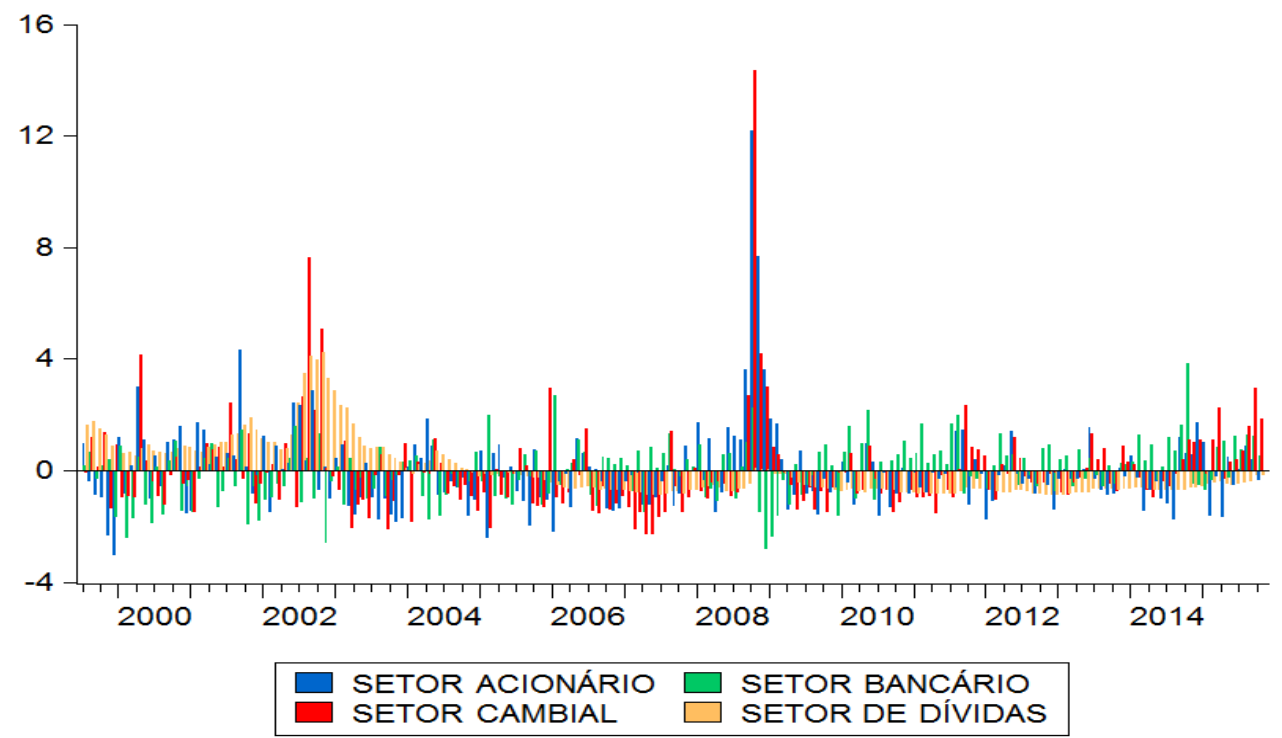

Fonte: Resultados da pesquisa.

O primeiro deles, ocorrido entre julho e outubro de 1999, está associado às incertezas decorrentes do período inicial de adoção do regime de metas na economia brasileira $^{18}$. Como pode ser observado a partir da Figura 3 e Tabela 1, o setor de dívidas foi o componente principal nesse primeiro episódio de instabilidades de maior duração que impactou a economia brasileira. A incerteza quanto à capacidade do país em conseguir controlar e manter a inflação estável refletiu diretamente no valor do EMBI Brasil +, cuja média para os quatro primeiros meses foi de 1033

(18) Para mais informações sobre os desafios na adoção do regime de metas de inflação no Brasil, ver Minella et al. (2002), Minella et al. (2003) e Agénor e Silva (2013). 
pontos, aproximadamente, enquanto que no período posterior, entre janeiro e abril de 2000, a média foi de 699 pontos, aproximadamente. Esses aumentos no valor do EMBI Brasil + traduziram os aumentos das expectativas de perdas futuras de aplicações em títulos da dívida pública brasileira e a perda de confiança nesse contexto de transição de regimes monetários na economia. Cabe ressaltar que a crise cambial, ocorrida meses antes do início do regime de metas e que levou à adoção do câmbio flutuante, provocou elevação da pressão sobre a taxa de câmbio e o aumento da volatilidade. Dessa forma, o setor cambial também contribuiu para a elevação do F.S.I. nesse período.

O estresse financeiro ocorrido entre junho e outubro de 2002 está associado à crise de confiança na economia brasileira em virtude da conjuntura eleitoral referente à primeira eleição do ex-presidente Lula. A Figura 3 e a Tabela 1 evidenciam a forte participação das pressões na taxa de câmbio durante o cenário de estresse financeiro, seguida pelo setor de dívidas e, em menor escala, o setor acionário. A crise de confiança teve como consequência uma elevada desvalorização da moeda brasileira, que atingiu seu valor máximo em outubro de 2002, cotada a $\mathrm{R} \$ 3,96 / 1 \mathrm{US} \$$, fato que promoveu forte pressão cambial. Os níveis de reservas em dólares entre os anos de 1999 e 2005 foram os mais baixos ao longo de todo o regime de metas para inflação no Brasil, cujo saldo médio foi de 43,32 bilhões de US\$, de acordo com dados do Bacen (2015). Dessa forma, as intervenções da autoridade monetária para conter parte da excessiva desvalorização da moeda brasileira foram limitadas pelo baixo nível de reservas internacionais.

A perda de confiança na economia brasileira pelos investidores ao longo deste período refletiu-se também no setor de dívidas externas, expresso no presente trabalho pelo índice EMBI + Brasil, que corresponde ao diferencial nos prêmios que devem ser pagos por títulos da dívida externa brasileira em relação a papéis de prazo equivalente do Tesouro dos Estados Unidos. O valor do EMBI + Brasil atingiu seu maior valor histórico de 2039 pontos em setembro de 2002, segundo dados do Instituto de Pesquisa Econômica Aplicada - Ipea (2015). Dessa forma, o cenário instável refletiu diretamente nas expectativas de aumento de perdas futuras, contribuindo para elevação do spread visto pelo índice EMBI + Brasil. Soma-se a isso o elevado endividamento externo do Brasil, cuja dívida externa líquida do governo federal correspondia a 19,80\% do Produto Interno Bruto (PIB), em setembro de 2002, segundo dados do Bacen $(2015)^{19}$. Cabe salientar, também, que parte da dívida pública interna federal era composta por títulos cambiais, em que cerca de $29 \%$ da dívida interna pública estava atrelada ao câmbio no $3^{\circ}$ trimestre de 2002 (Bacen, 2015). Portanto, o cenário de desvalorização cambial contribuía para o

(19) Para fins de comparação, em maio de 2004, essa dívida correspondia a 12,44\% do PIB, enquanto que, em setembro de 2008, representava $3,51 \%$ do PIB e, em fevereiro de 2015, essa proporção foi de 2,02\%, de acordo com dados do Bacen (2015). 
aumento das dívidas, impactando assim no aumento do prêmio de risco, como verificado pelo EMBI+Brasil.

Por fim, o setor acionário também refletiu, em menor escala, o cenário de desconfiança política e econômica em 2002. A volatilidade do índice IBovespa, principal indicador do mercado acionário brasileiro, elevou-se 34,66\%, entre maio e setembro de 2002, enquanto que o retorno do mesmo índice sofreu redução de $977,02 \%$ no mesmo período. Tais fatos evidenciam o movimento de fuga para a segurança e liquidez dos investidores nesse cenário de instabilidade.

O terceiro, e mais expressivo, episódio de estresse financeiro identificado refere-se ao período entre setembro e dezembro de 2008. Este episódio de estresse está relacionado aos impactos da crise financeira do subprime, iniciada na economia norte-americana em 2007, sobre a economia brasileira ${ }^{20}$. A falência do banco de investimentos Lehman Brothers, quarto maior banco de investimento dos EUA, em setembro de 2008, marca a transformação da crise financeira para uma crise global. Até então, os efeitos da crise haviam sido transmitidos apenas para os países desenvolvidos, sendo os mercados emergentes pouco afetados. Porém, com o caráter sistêmico adquirido em meados de 2008, as economias emergentes - mesmo aquelas com situação externa favorável, contas fiscais sólidas e inflação sob controle, como era o caso da economia brasileira - foram atingidas pela crise (Cintra; Prates, 2011).

A análise da Figura 3 mostra que o estresse financeiro decorrente da crise do subprime foi fortemente impulsionado por instabilidades no setor cambial e acionário, e em menor grau pelo setor bancário. Os estresses no setor cambial se deram em função do aumento da aversão aos riscos e da preferência pela liquidez por parte dos investidores estrangeiros, que fizeram com que a economia brasileira presenciasse um movimento súbito de fuga de capitais em decorrência do aumento da incerteza. Segundo dados do Bacen (2015), o investimento estrangeiro em carteira líquido apresentou uma redução de aproximadamente $581 \%$ entre o terceiro e o quarto trimestre de 2008. Esses fatores contribuíram para o processo de desvalorização da moeda brasileira, que entre setembro e outubro de 2008 desvalorizou-se 29,6\%, segundos dados do Bacen (2015), promovendo, assim, instabilidades no setor cambial.

Em relação aos estresses no setor acionário, a maior vulnerabilidade do setor de ações brasileiro, característica dos mercados emergentes, em relação às saídas de capitais em momentos de instabilidades financeiras impactaram diretamente os ativos negociados nesse mercado. Pelo fato de os ativos destas economias não apresentarem as características necessárias avaliadas pelos investidores, a fuga de capitais em decorrência da busca por segurança e liquidez ocasionou maior

(20) Os trabalhos de Pochmann (2009), Ipea (2009) e Freitas (2009) analisam os efeitos da crise do subprime em diversos setores da economia brasileira. 
volatilidade nos respectivos setores acionários. Entre agosto e outubro de 2008, o IBovespa apresentou elevação da volatilidade em 203,88\%, enquanto os retornos reduziram 136,52\%, de acordo com dados da BM\&FBovespa (2015), traduzindo, assim, a aversão ao risco e preferência pela liquidez por parte dos investidores, bem como a redução dos valores fundamentais de ações que compõem o índice ${ }^{21}$.

Por fim, a saída de capitais da economia brasileira gerou estresses no setor bancário, de modo que a aversão ao risco e preferência pela liquidez resultou no "empoçamento" do crédito bancário, refletido nas pequenas e médias instituições. As restrições ao crédito doméstico e internacional são fatores marcantes das economias emergentes, atingindo principalmente o setor bancário. Segundo Freitas (2009), o congelamento dos mercados interbancários e financeiros internacionais e a desvalorização do real, ao longo da crise do subprime, conduziram à rápida deterioração dos bancos que contraíram o crédito, restringindo a liquidez. De acordo com o estudo do Bacen (2009), Relatório de Economia Bancária e Crédito, um dos efeitos da crise sobre o Brasil foi a redução das linhas de crédito internacionais oferecidas ao país. Ainda segundo o relatório, os repasses de créditos externos pelas instituições do Sistema Financeiro Nacional apresentaram redução dos seus saldos de US\$ 46,8 bilhões, em junho de 2008, para US\$ 31,5 bilhões, em dezembro de 2009.

No ano de 2011, mais especificamente entre os meses de agosto e novembro, a economia brasileira sofreu um novo episódio de estresse financeiro, dessa vez associado à crise na zona do euro ${ }^{22}$. Como ressaltado pelo estudo do Bacen (2011), Relatório de Estabilidade Financeira, o agravamento da situação fiscal na Europa e o aumento das incertezas sobre o processo de recuperação global induziram a elevação da aversão ao risco e da demanda por ativos líquidos e de baixo risco, como os títulos do tesouro Americano, determinando a valorização do dólar em relação ao real, ao euro e a diversas outras moedas. Dessa forma, como mostrado na Figura 3, os principais propulsores do estresse financeiro nesse período foram as pressões nos setores cambial e acionário. Ainda segundo o relatório do Bacen (2011), o ambiente externo conturbado, devido, entre outros fatores, à situação fiscal delicada dos países periféricos da Zona do Euro, levou os investidores estrangeiros a reduzirem suas posições no período - o fluxo líquido no primeiro semestre foi negativo em $\mathrm{R} \$ 1,1$ bilhão. As pressões sobre o Real elevaram-se 33,13\%, entre julho e setembro de 2011, e a volatilidade da taxa de câmbio aumentou 169,80\% no mesmo período. Em relação ao setor acionário, as incertezas dos investidores e o movimento da fuga de

(21) Entre as empresas que compõem o IBovespa, o valor das ações de diversas delas foi fortemente impactado pela redução no preço das commodities durante a crise do subprime, como foi o caso do setor mineral e petrolífero.

(22) Galí (2010) e Lane (2012) fornecem ampla discussão sobre as causas e especificidades da crise na zona do euro. 
investimentos para mercados mais líquidos e seguros causaram elevação de $101,17 \%$ na volatilidade do IBovespa, entre julho e setembro de 2011.

O último episódio de estresse financeiro de maior duração identificado pelo F.S.I. na economia brasileira ocorreu no fim de 2014, entre os meses de setembro e dezembro, o qual está relacionado ao cenário instável político e econômico devido ao processo de sucessão presidencial, ocorrido em outubro do mesmo ano. O cenário de estresse neste período esteve associado principalmente aos setores acionário e bancário. $\mathrm{O}$ ambiente de incertezas fez com que os investidores optassem por mercados mais seguros, afetando diretamente os retornos e volatilidades das ações negociadas no mercado acionário do Brasil. Segundo dados do Bacen (2015), o investimento estrangeiro em carteira líquido, em novembro de 2015, foi negativo em US\$ 18,5 milhões, afetando diretamente a volatilidade do IBovespa, cuja elevação foi de $106,69 \%$, entre agosto e novembro. Outro fator que impactou diretamente na elevação da volatilidade do IBovespa foi a crise na Petrobrás. O esquema de corrupção na maior empresa estatal brasileira, que tornou-se público a partir de março de 2014, fez com que as ações da empresa na bolsa de valores apresentassem acentuada desvalorização. Com participação média de $10 \%$, aproximadamente, no IBovespa, o preço das ações da Petrobrás ${ }^{23}$ passou de $\mathrm{R} \$ 23,29$, no dia 02 de setembro, para R \$ 8,52, em 15 de dezembro. A desvalorização de 63,42\%, mostrada anteriormente, contribuiu para elevação da volatilidade do IBovespa e refletiu a insegurança dos investidores em manter ações da estatal brasileira.

Além dos estresses no setor acionário, o setor bancário também sofreu os efeitos da instabilidade política e econômica interna. Em alguns períodos o beta do setor bancário apresentou valor superior a 1 , indicando que a volatilidade dos retornos das ações bancárias foi maior que a volatilidade dos retornos totais do mercado global - medido pelo IBovespa, o que sugere que o setor bancário apresentou-se, relativamente, mais arriscado.

De modo geral, o índice de estresse financeiro para a economia do Brasil mostrou-se útil na identificação das principais crises que atingiram a economia, uma vez que os picos no F.S.I. se associaram a eventos bem conhecidos que impactaram todo o sistema financeiro. Como ressaltado por Illing e Liu (2003), dependendo da sua natureza, as situações de estresse extremo podem ser referidas como crises.

Contudo, outros 21 episódios causaram estresses financeiros com duração de um ou dois meses, sendo representados pelas áreas sombreadas claras na Figura 3. A análise desses episódios de menor duração na economia, e que não estiveram associados a crises para o país, auxiliam no entendimento das causas dessas

(23) Ações Petrobrás (ON), cujo símbolo de negociação é PETR3. O Índice IBovespa é composto também pelas Ações Petrobrás (PN), representada pelo símbolo PETR4, que em conjunto com as ações PETR3 representam $9,85 \%$ do IBovespa. 
instabilidades e como elas evoluíram ao longo do regime de metas no Brasil. Cardarelli et al. (2011) ressaltam que apenas os episódios de estresse financeiro com grandes consequências para a economia e/ou intervenções públicas receberam atenção na última década, sendo que os episódios em menor escala são muitas vezes negligenciados e poderiam, por sua vez, servirem como úteis episódios contrafactuais para a política monetária. A Tabela 2 apresenta esses episódios de menor duração divididos em três períodos ao longo do regime de metas.

Tabela 2

Episódios de estresses financeiros de curta duração no Brasil, períodos 1999-2004, 2005-2009 e 2010-2015

\begin{tabular}{|c|c|c|c|c|}
\hline & \multicolumn{4}{|c|}{ Número de episódios de curta duração } \\
\hline & Total & 1999-2004 & 2005-2009 & 2010-2015 \\
\hline Estresse financeiro & 21 & 8 & 5 & 8 \\
\hline \multicolumn{5}{|l|}{ Principal setor: } \\
\hline Bancário & 5 & 3 & 1 & 1 \\
\hline Acionário & 6 & 2 & 2 & 2 \\
\hline Cambial & 10 & 3 & 2 & 5 \\
\hline Dívidas & - & - & - & - \\
\hline \multicolumn{5}{|l|}{ Elevação secundária: } \\
\hline Bancário & 7 & 3 & 1 & 3 \\
\hline Acionário & 10 & 3 & 2 & 5 \\
\hline Cambial & 7 & 4 & - & 3 \\
\hline Dívidas & - & - & - & - \\
\hline
\end{tabular}

Fonte: Resultados da Pesquisa.

Foram identificados 21 episódios de estresses financeiros com duração de um ou dois meses, dos quais 10 foram impulsionados majoritariamente por instabilidades decorrentes do setor cambial. Na Figura 3 é possível verificar a parcela do setor de câmbio, representada pela área em azul, nos períodos de picos do F.S.I., ao longo do período analisado. Uma possível explicação para a predominância da pressão sobre o Real e o aumento da volatilidade da moeda brasileira no período inicial do regime de metas reside no fato do país apresentar nesse período baixas reservas internacionais, o que limitou a ação da autoridade monetária em conter desvalorizações excessivas da moeda frente ao dólar. Segundo dados do Bacen (2015), entre julho de 1999 e julho de 2006, o país apresentou uma média de 44,76 bilhões de dólares em reservas, valor inferior ao apresentado entre janeiro de 2010 a fevereiro de 2015, quando o país apresentou, em média, 342,25 bilhões de dólares. Tal fato, aliado ao fluxo de capitais estrangeiros em cenários economicamente instáveis, que migram de economias emergentes rumo a mercados com maior liquidez e segurança, pressionam a taxa de câmbio dessas economias, como 
verificado para o Brasil nesses dois períodos. Neste contexto, Akyüz e Cornford (1999) alertam para os efeitos mais significativos entre os mercados financeiros das economias emergentes diante dos fluxos de capitais potencialmente instabilizadores. Por fim, no período entre 2010 e 2015, as pressões no setor cambial foram as principais responsáveis por cinco de um total de oito cenários de estresses financeiros identificados. Apesar do nível de reservas internacionais ter se elevado substancialmente nesse período, chegando ao valor máximo em agosto de 2014 (U\$S 379,15 bilhões), tal fato não impediu que a moeda brasileira sofresse pressões, além de apresentar elevação da volatilidade, mais recorrente a partir de setembro de 2014.

Esse comportamento corrobora a maior vulnerabilidade da economia brasileira diante dos fluxos de capitais internacionais que promovem instabilidades na economia e justifica a importância de se analisar as instabilidades no setor cambial como fontes potenciais de estresses no mercado financeiro.

Quanto aos setores acionário e bancário, estes foram os principais responsáveis por seis e cinco episódios, respectivamente, de instabilidades financeiras de menor duração na economia. A maior predominância das instabilidades no setor bancário se deu nos anos iniciais do regime de metas, enquanto que para o setor acionário esse comportamento foi mais homogêneo ao longo de todo o período.

Cabe ressaltar a presença de dois episódios de estresses financeiros no ano de 2015, ambos associados à crise política e econômica brasileira. O primeiro deles, ocorrido em março de 2015, esteve associado principalmente ao mercado acionário, assim como o período de estresse de maior duração em meados de 2014 . O último episódio, nos meses de agosto e setembro de 2015, por sua vez, teve como principal impulsionador o setor cambial. Desse modo, uma importante particularidade da recente crise pode ser destacada, a saber: a crise iniciou com pressões no setor acionário, motivada entre outros fatores pela falta de segurança dos investidores na economia brasileira em virtude da sucessão presidencial e pela crise da Petrobrás, fato que provocou uma queda vertiginosa no valor das ações dessa estatal, bem como no IBovespa. Porém, as instabilidades no mercado cambial passaram a ganhar relevância, muito em função da interligação entre os mercados acionário e cambial no sistema financeiro. Assim, o que se viu foi a continuação das pressões no mercado acionário, porém essa pressão não foi a mais relevante para a ocorrência dos episódios de estresses, sendo essa parcela atribuída ao setor cambial. Desse modo, as intensas desvalorizações da moeda brasileira em meados de 2015, e a excessiva volatilidade da taxa de câmbio, fizeram com que as pressões no setor cambial fossem as principais fontes de instabilidades no último episódio de estresse financeiro identificado na economia brasileira. 


\section{Considerações finais}

O presente trabalho introduziu uma estimativa ordinal dos estresses financeiros sob a forma de um índice, o Índice de Estresse Financeiro (F.S.I.), construído a partir de uma adaptação do índice proposto por Balakrishnan et al. (2009). O F.S.I. mostrou um bom desempenho na identificação de episódios amplamente reconhecidos de estresse financeiro na economia brasileira ao longo do regime de metas. Foram identificados 5 episódios de estresse com duração igual ou superior a três meses, dos quais 4 estiveram associados a crises que impactaram a economia, a saber: crise de confiança, entre junho e outubro de 2002; crise do subprime, entre setembro e dezembro de 2008; crise da zona do euro, entre agosto e novembro de 2011, e crise política e econômica, entre setembro e dezembro de 2014.

Em suma, as instabilidades nos setores cambial e acionário potencializaram os principais episódios de estresses financeiros que atingiram a economia brasileira, entre julho de 1999 e outubro de 2015. Os resultados encontrados corroboram o fato da economia brasileira, assim como as demais economias emergentes, apresentar elevada dependência de capitais externos, contribuindo para a geração de instabilidades e pressões na taxa de câmbio em virtude da saída de capitais em momentos financeiramente instáveis. Soma-se a isso o comportamento mais avesso ao risco por parte dos investidores, ao optarem por mercados mais seguros em momentos de estresses financeiros, e, assim, gerar instabilidades no setor de ações.

Outro importante resultado obtido com a utilização do F.S.I. foi a identificação de 21 episódios de estresse financeiro na economia brasileira com duração de um ou dois meses. A análise desses episódios de curta duração, e que não estiveram associados a crises, permitiram inferir sobre como as instabilidades financeiras evoluíram ao longo do regime de metas na economia brasileira. Entre os anos de 1999 e 2015, a maioria dos episódios de estresses financeiros esteve associada ao setor cambial. Tal fato ratifica a maior vulnerabilidade e dependência do sistema financeiro brasileiro diante do fluxo de capitais externos. Cabe ainda ressaltar a influência indireta exercida pelo mercado cambial sobre os mercados bancário e acionário, como identificado pelas elevações secundárias nesses dois últimos mercados nos episódios de estresses financeiros, seja através dos balancetes dos bancos comerciais e empresas, ou afetando ativos e passivos cotados em moeda estrangeira.

De modo geral, os resultados mostraram que o F.S.I. pode ser uma ferramenta útil para o Banco Central do Brasil no contexto de identificação de episódios que gerem instabilidades financeiras na economia, além de possibilitar o monitoramento dos setores que passem a apresentar uma contribuição significativa para a elevação do índice, como forma de uma política preventiva frente às possíveis crises que possam surgir. Além disso, a autoridade monetária pode, através de uma 
análise contrafactual, inferir sobre a gravidade de um episódio de estresse financeiro específico, ao comparar o valor do F.S.I. de um determinado episódio com valores de episódios amplamente reconhecidos associados às crises financeiras, como a crise do subprime, no ano de 2008.

\section{Referências bibliográficas}

AGÉNOR, P. R.; SILVA, L. A. P. Inflation targeting and financial stability: a perspective from the developing world. Brasília: Banco Central do Brasil, 2013. (Working Paper Series, n. 324).

AKYÜZ, Y.; CORNFORD, A. Capital flows to developing countries and the reform of the international financial system. United Nations Conference on Trade and Development (UNCTAD), 1999. (Discussion Papers, n. 143).

APOSTOAIE, M. C.; CUZA, C. Consideration on the price stability - financial stability relationship in the context of financial globalization. Studies and Scientifica Researches, v. 15, p. 6-13, 2010.

BACEN - Banco Central do Brasil. Relatório de Economia Bancária $e$ Crédito. Brasília: 2009. Disponível em: https://www.bcb.gov.br/pec/depep/spread/REBC2009.pdf. Acesso em: 20 fev. 2015.

BACEN - Banco Central do Brasil. Relatório de Estabilidade Financeira, Brasília, v. 10, n. 2, 2011. Disponível em: http://www.bcb.gov.br/htms/estabilidade/2011_09/refP.pdf. Acesso em: 21 fev. 2015.

BACEN - Banco Central do Brasil. Sistema Gerenciador de Séries Temporais, 2015. Disponível em: http://www4.bcb.gov.br/pec/series/port/aviso.asp. Acesso em: 20 abr. 2015.

BALAKRISHNAN, R.; DANNINGER, S.; ELEKDAG, S.; TYTELL, I. The transmission of financial stress from advanced to emerging economies. IMF, 2009. (Working Paper, n. 09/133).

BAUWENS, L.; LAURENTE, S.; ROMBOUTS, J. V. K. Multivariate Garch models: a survey. Journal of Applied Econometrics, v. 26, n. 4, p. 79-109, 2006.

BAXA, J.; HORVÁTH, R.; VASÍCEK, B. Time-varying monetary-policy rules and financial stress: does financial instability matter for monetary policy. Journal of Financial Stability, v. 9, n. 1, p. 117-138, 2013.

BM\&FBOVESPA - Bolsa de Valores, Mercadorias e Futuros. Índices de ações do mercado brasileiro. 2015. Disponível em: www.bmfbovespa.com.br. Acesso em: 18 maio 2015. 
CARDARELLI, R.; ELEKDAG, S.; LALL, S. Financial stress and economic contractions. Journal of Financial Stability, v. 7, n. 2, p. 78-97, 2011.

CHAKRABORTY, L. S. Fiscal consolidation, budget deficits and the macro economy. Nova Deli: Sage Publications, 2016.

CHANT, J. Essay of financial stability. Bank of Canada, 2003. (Technical Report n. 95). Disponível em: http://www.banqueducanada.ca. Acesso em: 11 jan. 2015.

CINTRA, M. A. M.; PRATES, D. M. Os países em desenvolvimento diante da crise financeira global. In: ACIOLY, Luciana; LEÃO, Rodrigo Pimentel Ferreira (Org.). Crise financeira global. Ipea, 2011. p. 11-46, 2011.

DAS, U.; QUINTYN. M.; CHENARD, K. Does regulatory governance matter for financial system stability? An empirical analysis. IMF, 2004. (Working Paper, n. 04/89).

DAS, U.; YOSSIFOV, P.; PODPIERA, R.; ROZHKOV, D. L. Quality of financial policies and financial system stress. IMF, 2005. (Working Paper, n. 05/173).

ECB - EUROPEAN CENTRAL BANK. Financial stability review. 2009. Disponível em: http://www.ecb.europa.eu. Acesso em: 14 jun. 2015.

ENGLE, R. F.; KRONER, K. F. Multivariate simultaneous generalized ARCH. Econometric Theory, v. 11, n. 1, p. 122-150, 1995.

FREITAS, M. C. P. Os efeitos da crise global no Brasil: aversão ao risco e preferência pela liquidez no mercado de crédito. Estudos Avançados, v. 23, n. 66, p. 125-145, 2009.

GALÍ, J. Notes on the Euro Debt Crisis. 2010. Disponível em: http://crei.cat/people/gali/debt\%20crisis\%2003\%2006.pdf. Acesso: 30 jun. 2015.

GOODHART, C.; OSORIO, C.; TSOMOCOS, D. An analysis of monetary policy and financial stability: a new paradigm. 2009. (CESifo Working Paper, n. 2885).

HAKKIO, C. S.; KEETON, W. R. Financial stress: what is it, how can it be measured, and why does it matter? Economic Review, n. 2, p. 5-50, 2009.

HODRICK, R. J.; PRESCOTT, E. C. Postwar U.S. business cycles: an empirical investigation. Journal of Money, Credit And Banking, v. 29, n. 1, p. 1-16, 1997.

HOUBEN, A.; KAKES, J.; SCHINASI, G. Toward a framework for safeguarding financial stability. 2004. (IMF Working Paper, n. 04/101).

ILLING, M.; LIU, Y. An index offinancial stress for Canada. Bank of Canada, 2003. (Working Paper, n. 14).

ILLING, M.; LIU, Y. Measuring financial stress in a developed country: an application to Canada. Journal of Financial Stability, v. 2, n. 3, p. 243-265, 2006. 
IMF - INTERNATIONAL MONETARY FUND. Bulgaria: Selected Issues. IMF, 2007. (Country Report, n. 07/390).

IMF - INTERNATIONAL MONETARY FUND. World Economic Outlook, Oct. 2008.

IPEA - INSTITUTO DE PESQUISA ECONÔMICA APLICADA. Crise internacional: reações na América Latina e canais de transmissão no Brasil. Ipea, Brasília: fev. 2009. (Comunicado da Presidência, n. 17).

IPEA - INSTITUTO DE PESQUISA ECONÔMICA APLICADA. Ipeadata macroeconômico. 2015. Disponível em: http://www.ipeadata.gov.br/. Acesso em: 06 mar. 2015.

LANE, P. R. The European sovereign debt crisis. The Journal of Economic Perspectives, v. 26, n. 3, p. 49-68, 2012.

LAURENT, S. G@RCH 6. Estimating and forecasting ARCH models. London: Timberlake Consultants Press, 2009.

MATHWORKS. Econometrics Toolbox. 2016. Disponível em: https://www.mathworks.com/help/econ/hpfilter.html. Acesso em: 03 jan. 2017.

MINELlA, A.; FREITAS, P. S.; GOLDFAJN, I.; MUINHOS, M. K. Inflation targeting in Brazil: lessons and challenges. Brasília: Banco Central do Brasil, 2002. (Working Paper Series, n. 53).

MINELlA, A.; FREITAS, P. S.; GOLDFAJN, I.; MUINHOS, M. K. Inflation targeting in Brazil: constructing credibility under exchange rate volatility. Brasília: Banco Central do Brasil, 2003. (Working Paper Series, n. 77).

MISHKIN, F. Is monetary policy effective during financial crises? American Economic Review, v. 99, n. 2, p. 573-577, 2009.

PAPADEMOS, L. Financial stability and macro-prudential supervision: objectives, instruments and the role of the ECB. CFS conference "The ECB and Its Watchers XI”, 2009. Disponível em: http://www.ecb.europa.eu/. Acesso em: 12 jul. 2015.

PARK,C. Y.; MERCADO JR, R. V. Determinants of Financial Stress in Emerging Market Economies. Journal of Banking \& Finance, v. 45, p. 199-224, 2014.

POCHMANN, M. A crise internacional e seus efeitos no Brasil. In: BISPO, C. R.; MUSSE, J. S.; VAZ, F. T.; MARTINS, F. J. (Org.). Crise financeira mundial: impactos sociais e no mercado de trabalho. Brasília: Anfip, 2009. p. 11-46.

SALES, A. S.; AREOSA, W. D.; AREOSA, M. B. M. Some financial stability indicators for Brazil. Brasília: Banco Central do Brasil, 2012. (Working Paper Series, n. 287). 
SCHINASI, G. J. Defining financial stability. 2004. (IMF Working Papers, 4/187).

SILVA, L. A. P.; SALES, A. S.; GAGLIANONE, W. P. Financial stability in Brazil. Banco Central do Brasil, 2012. (Working Paper Series, n. 289).

STIGLITZ, J. E.; OCAMPO, J.; SPIEGEL, S; FRENCH DAVIS, R.; NAYYAR, D. Stability with growth: macroeconomics, liberalization and development. New York: Oxford Univ. Press, 2006.

SY, A. N. R. Rating the rating agencies: anticipating currency crises or debt crises? Journal of Banking \& Finance, v. 28, n. 11, p. 2845-2867, 2004.

TERRA, M. C.; SOIHET, E. Índice de controles de capitais: uma análise da lesgislação e seu impacto sobre o fluxo de capital no brasil no período 1990-2000. Estudos Econômicos, São Paulo, v. 36, n. 4, p. 721-745, 2006.

TSAY, R. S. Analysis of financial time series. 3. ed. New Jersey: Wiley, 2010. 687p. 


\section{Apêndice}

Figura A.1

Variâncias condicionais estimadas para o retorno do setor acionário, 01/07/1999 a 30/10/2015

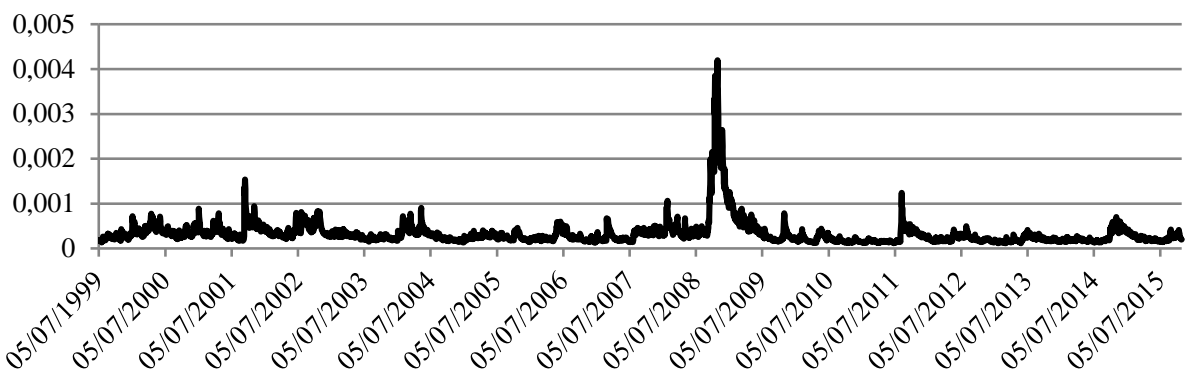

(a) $\operatorname{GARCH}(3,3)$

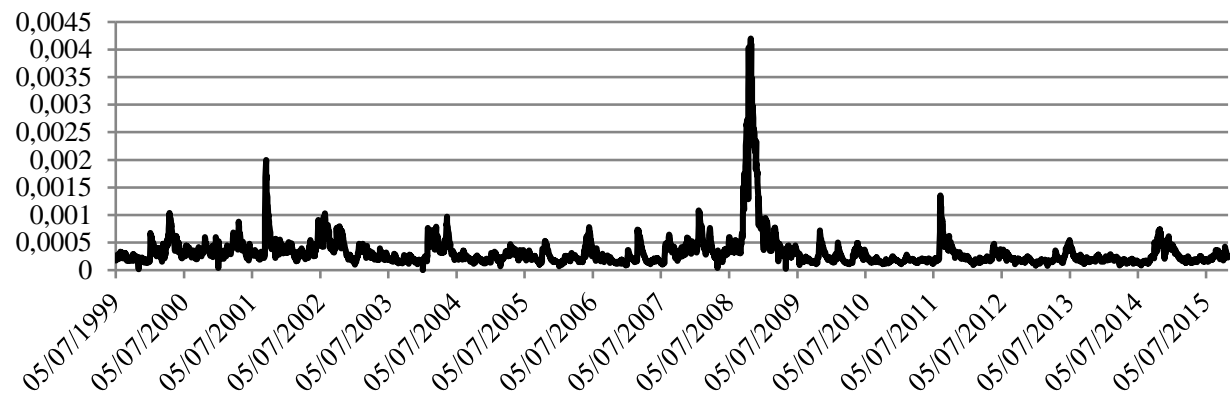

(b) TARCH $(2,2)$

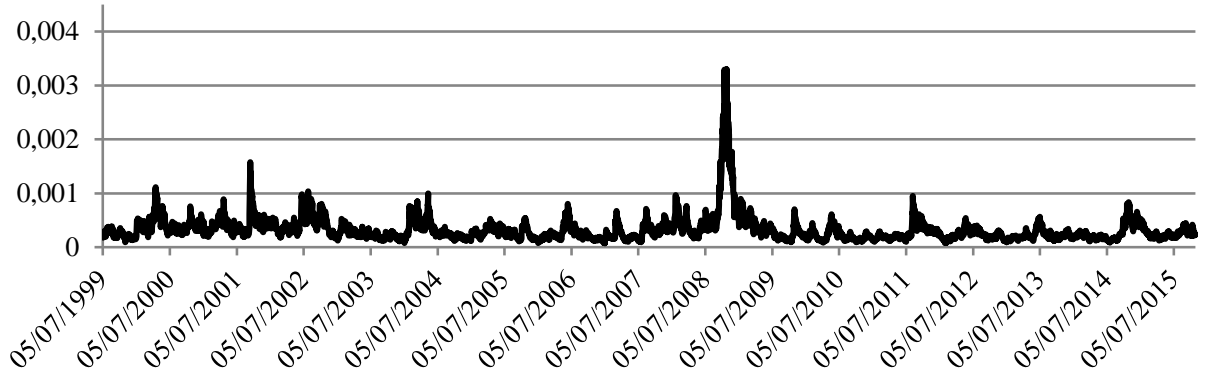

(c) $\operatorname{EGARCH}(2,2)$

Fonte: Resultados da Pesquisa. 